\title{
Effect of Gliricidia sepium leaves extracts on Aedes aegypti: Larvicidal activity
}

\author{
K. V. Krishnaveni, R. Thaiyal Nayaki, M. Balasubramanian* \\ Department of Biotechnology, K.S. Rangasamy College of Technology, Tiruchengode, Namakkal, Tamil Nadu, India
}

Received: 15.06.2015

Accepted: 20.10 .2015

Published: 05.12 .2015

*Address for correspondence:

M. Balasubramanian, Department of

Biotechnology,

K.S. Rangasamy

College of Technology,

Tiruchengode - 637215 ,

Tamil Nadu, India.

Tel: 091-4288-274741,

Fax: 091-04258-274860,

E-mail: balasubramanianm@ gmail.com

\begin{abstract}
Mosquitoes are the single most important group of insects in terms of the public health significance and causing diseases. They are the vectors for the transmission of many viral pathogens and pose serious threat to human health. Chemical insecticides are widely used, but they are non-selective and harmful to beneficial organisms. In the present study, Gliricidia sepium leaves extracts were used to analyze its effect against Aedes aegypti, to compare the mortality rate while using different solvent extracts of the leaf, to identify the solvent extract which give a high rate of larval mortality, and to characterize the compounds present in the corresponding leaf extract using phytochemical analysis. The ethanolic extract of $G$. sepium leaves constitutes flavonoids, steroids, glycoside, carbohydrate, and saponins compound. Thus, it was found to have an inhibitory effect on the growth of larvae than other solvent extracts. In the statistical analysis, the highest significant difference was observed between 1.5 and $2.0 \mathrm{~g} / \mathrm{l}$ concentration of ethanolic extract and other extracts. However, no significant difference was observed in other concentrations. The larvicidal activity of the plant extract may be attributed to the presence of active compounds such as terpenoids, saponins, and steroids.
\end{abstract}

KEY WORDS: Aedes aegypti, Gliricidia sepium, larvicidal, mortality rate, phytochemical

\section{INTRODUCTION}

Mosquitoes are the single most important group of insects in terms of public health significance and causing diseases such as malaria, dengue fever, Japanese encephalitis, and other fevers (Kamaraj et al., 2011). India is endemic to mosquito-borne diseases due to the favorable ecological conditions. They are the vectors for the transmission of many viral pathogens and pose serious threat to human health (Arthi and Murugan, 2012). It is very difficult to control these vectors due to their remarkable ability to adapt to various environments, their close contact with humans, and their reproductive biology. The rich organic content, stagnant water, low illumination, and small orifice of the coconut shells in rubber plantations favor intense breeding (Honorio et al., 2006).

Dengue fever continues to be a major public health problem in the countries ofWestern Pacific and Southeast Asia. The increasing trend of dengue outbreaks accompanied by DHF is posing a problem of outmost importance to the public health of India (Fulmali et al., 2008). There has been an outbreak of chikungunya and dengue all over India from 2006 to 2009 (Arunachalam et al., 2008).
The mosquito Aedes aegypti, an important vector of arboviruses such as a dengue fever, urban yellow fever, and chikungunya is a holometabolous insect processing a life cycle with four instar stages: Egg, four larval instars, pupa, and adult (Kaushik and Saini, 2008). Being fundamentally aquatic, this mosquito reaches the terrestrial environment only as an adult. Its preference for humans as a host is an important factor for transmission. Thus, environmental assessment at the household level is necessary for dengue control.

Insecticide applications that were highly effective against the vector control are facing a threat due to the development of resistance to chemical insecticides resulting in rebounding vectorial capacity. However, they are non-selective and potentially harmful to other beneficial organisms. Concerning A. aegypti control, in addition to, the recommended mechanical elimination of breeding sites, those permanent recipients that cannot be discarded are generally treated with chemical insecticides (Srivastava et al., 2008). Most of these insect repellents and bug sprays used are poisonous and cause health problems especially for the children (suffocation). 
The larvicidal activity of extracts from leaves, flowers, and roots of many plants were reported in many studies. The phytochemical screening of those plants for saponins, flavonoids, terpenoids, tannins, cardiac glycosides, and steroids are also carried out (Joji Reddy and Beena, 2010). Gliricidia sepium often simply referred to as Gliricidia is a medium size leguminous tree belonging to the family Fabaceae. The active medical compounds present in Gliricidia are afrormosin, medicarpin, tannin, and some isoflavins. Tannin is reported to have antidiarrheic, antidysentric, antimutagenic, antinephritic, antiviral, bacterial, cancer preventive, hepato-protective, pesticide, psycotrophic, and viricide activities (Akharay et al., 2012). The leaves of Gliricidia are used in south India as a mosquito repellent, and they have antifungal and antibacterial activity. Various phytochemicals such as flavonoids, triterpenoid, coumarin, coumaric acid, melilotic acid, and stigmastanol glucoside have been identified and isolated from various parts of this plant. 42 known compounds are found in the leaves and flowers of G. sepium (Joji Reddy and Beena, 2010).

In the present study, we sought to determine the effect of G. sepium leaves extract can be used for mosquito control. Different solvent extracts of the leaves of Gliricidia are compared for their ability to make the desired mortality rate in the A. aegypti. Many researchers are proceeding to use natural insecticides for the control of mosquitoes and may thus contribute for the control of vector transmitted diseases such as malaria, dengue fever, and many others.

\section{MATERIALS AND METHODS}

\section{Collection of Sample}

The leaves of G. sepium were collected from the Kerala Agricultural University, Mannuthy, Kerala, India. The first instar larvae of $A$. aegypti were collected from the National Institute for Communicable Diseases, Mettupalayam, Tamil Nadu, India.

\section{Preparation of Extract}

The leaves of G. sepium were dried under shade and made into fine powder. To prepare the leaf extract, $30 \mathrm{~g}$ of leaf powder was immersed in $200 \mathrm{ml}$ of respective solvent (ethanol, acetone, toluene, and iso-propanol) by the cold extraction method. The solvents were selected based on the order of polarity. This mixture was kept in dark for $24 \mathrm{~h}$ at room temperature.

\section{Maintenance of Mosquito Larvae}

The larvae of $A$. aegypti were maintained at room temperature as reported earlier (Arthi and Murugan,
2012). The breeding cups were covered with wire mesh to avoid contact with foreign mosquitoes. The larvae were observed for the different instar stages, and the third instar larvae were used throughout the experiment.

\section{Phytochemical Analysis}

\section{Test for flavonoids}

To $1 \mathrm{ml}$ of aqueous extract, add $1 \mathrm{ml}$ of $10 \%$ lead acetate (Zoran et al., 2004). Formation of yellow precipitate indicated the presence of flavonoid.

\section{Test for steroids}

$2 \mathrm{ml}$ of organic extract was dissolved in $2 \mathrm{ml}$ of chloroform and was treated with sulfuric acid and acetic acid. The appearance of green confirmed the presence of steroids (Gowthami and Tamilselvi, 2012).

\section{Test for phlobatannins}

About $2 \mathrm{ml}$ of aqueous extract was added to $2 \mathrm{ml}$ of $1 \%$ hydrochloric acid, and the mixture was dried (Mehta et al., 2013). Deposition of red precipitate was taken as evidence for the presence of phlobatannins.

\section{Test for glycosides}

About $2 \mathrm{ml}$ of organic extract was mixed with $2 \mathrm{ml}$ of chloroform to which $2 \mathrm{ml}$ of acetic acid was added carefully. A color change from violet to blue to green indicated the presence of a steroidal nucleus that is aglycone portion of glycoside (Akharay et al., 2012).

\section{Test for carbohydrates}

To $3 \mathrm{ml}$ of aqueous extract, $1 \mathrm{ml}$ of iodine solution was added (Balasubramanian, 2012). A purple coloration at the interface indicated the presence of carbohydrates.

\section{Test for Saponins}

$5 \mathrm{ml}$ of aqueous extract was shaken vigorously with $5 \mathrm{ml}$ of distilled water in a test tube. The mixture was warmed for few minutes (Meena and Jolly, 2011). The formation of stable foam, honeycomb in shape was taken as the evidence for the presence of saponins.

\section{Larvicidal Activity of Leaf Extracts}

From the $10 \%$ stock solution of respective solvent leaf extract, 100-400 $\mu \mathrm{l}$ were added in $20 \mathrm{ml}$ of distilled water in the Petri plates (Abdelouaheb et al., 2009). Ten numbers of third instar larvae of $A$. aegypti were added to the above Petri plates. The control was also maintained by adding respective solvents in $20 \mathrm{ml}$ of water in a Petri plate. The larvae were fed with food which was a 
mixture of dog biscuit and yeast granules. The number of dead larvae was observed after $24 \mathrm{~h}$. This experiment was repeated three times, and the triplet values were recorded.

$$
\begin{gathered}
\text { Corrected } \\
\text { mortality }
\end{gathered}=\frac{\begin{array}{c}
\text { Observed mortality in treatment }- \\
\text { Observed mortality in control }
\end{array}}{100-\text { Control mortality }} \times 100
$$$$
\text { Mortality }(\%)=\frac{\text { Number of dead larvae }}{\text { Number of larvae introduced }} \times 100
$$

\section{Column Chromatography}

Column chromatography was done for the ethanolic extract of G. sepium. The silica 60-120 mesh was used as the stationary phase $(600 \mathrm{~mm} \times 30 \mathrm{~mm})$, and ethanol was used as mobile phase (Fang et al., 2002). $3 \mathrm{ml}$ fractions were collected and used to perform thin layer chromatography (TLC).

\section{TLC}

TheTLC plate was prepared manually in which chloroform, acetone, and methanol in the ratio 7:1:1 was used as mobile phase. The sample to be analyzed was spotted onto the plate and allowed to run via capillary action. It was then allowed to air dry. The sample spots were developed under iodine chamber and were located from which $\mathrm{Rf}$ value was calculated.

$$
\mathrm{Rf} \text { value }(\mathrm{cm})=\frac{\text { Distance moved by analyte }}{\text { Distance moved by solvent }}
$$

\section{RESULTS AND DISCUSSION}

\section{Phytochemical Screening of Ethanolic and Aqueous Extract of G. sepium}

The medicinal property variations among plants are due to the variation of family and genus in which they belong and the gene expression of bioactive compounds. Thus, the analysis of phytochemical compounds in the experimental plant should give more information about the plants. In the present study (Table 1), the phytochemical analysis of the ethanolic extract of G. sepium showed the presence of flavonoids, steroids, glycosides, carbohydrates, and saponins as reported earlier (Akharay et al., 2012). The presence of these phytochemicals in the leaf extract evaluates them strongly for the antibacterial activity of the plant (Ajaieoba, 2002).

\section{Larvicidal Activity of Different Solvent Extracts}

The phytochemical constituents of the G. sepium have been fractionated by four different polar solvents. These solvent extracts were checked for larvicidal activity and the positive control (mosquito in distilled water) and the negative control (mosquito insolvent) were maintained for all the solvents. The ethanol, iso-propanol, and acetone extracts were found to be active against $A$. aegypti, whereas toluene extract showed a negative result. The number of dead larvae was found to be more in a higher concentration of all extracts.

From the Table 2, the ethanol extract was found to be more effective than all other extracts. The plants extracts of Annona squamosa, Canarium indicum, and Tridax procumbens showed moderate effects against larvae of Anopheles subpictus and Culex tritaeniorhynchus after $24 \mathrm{~h}$ of exposure. The highest toxic effects were observed in $A$. squamosa bark methanol extract, $C$. indicum leaf ethyl acetate and methanol extract, and $T$. procumbens leaf acetone and ethyl acetate extract against the larvae of $A$. subpictus and C. Tritaeniorhynchus (Kamaraj et al., 2011).

The mortality percentage was studied at different instar stages of Culex quinquefasciatus, A. aegypti, Anopheles stephensi larvae using Millingtonia hortensis acetone leaf extract and the mortality rate of larvae was higher at initial stage than other stages of instar larvae (Kaushik and

Table 1: Qualitative phytochemical screening of G. sepium

\begin{tabular}{llc}
\hline Test & Observation & Result \\
\hline Flavonoids & Yellow precipitate & + \\
Steroids & Greenish & + \\
Phlobatannins & No red precipitate & - \\
Glycoside & Color change from violet to blue to green & + \\
Carbohydrate & Purple in the inter-phase & + \\
Saponins & Stable foam, honeycomb in shape & + \\
\hline
\end{tabular}

-: Absence, +: Presence, G. sepium: Gliricidia sepium

Table 2: Larvicidal activity of different solvent extracts of G. sepium

\begin{tabular}{lccc}
\hline Solvent extract & Volume $(\mu \mathrm{l})$ & Concentration $(\mathrm{mg} / \mathrm{l})$ & Mortality $(\%)$ \\
\hline Ethanol & 100 & 500 & 26.6 \\
& 200 & 1000 & 46.6 \\
& 300 & 1500 & 70 \\
Acetone & 400 & 2000 & 90 \\
& 100 & 500 & 3.3 \\
& 200 & 1000 & 20 \\
Iso-propanol & 300 & 1500 & 50 \\
& 400 & 2000 & 33.3 \\
& 100 & 500 & 13.3 \\
& 200 & 1000 & 33.3 \\
& 300 & 1500 & 63.3 \\
& 400 & 2000 & 46.6 \\
\hline
\end{tabular}

G. sepium: Gliricidia sepium 
Saini, 2008). Karthikeyan et al. (2012) reported that the second and third instars larvae of $C$. quinquefasciatus have low mortality by the Leucas aspera extract whereas Vitex negundo and Eucalyptus ethyl acetate and ethanol extracts have more larvicidal activity against $C$. quinquefasciatus (Karthikeyan et al., 2012). From the initial study of this work $A$. aegypti have a high mortality rate in ethanol extract, and Iso-propanol showed the least mortality rate at $2 g / l$ concentration. Therefore, the experiment was focused in the range of 1.5-2.0 g of ethanol extract. The mortality percentage was increased by plant extract in a dosage-dependent manner (Srivastava et al., 2003; Choochote et al., 2004; Singh et al., 2006).

\section{Statistical Analysis}

The bioassays were performed by taking 10 larvae in each plate.

According to the bar diagram (Figure 1), ethanolic extract showed highest mortality rate in the concentration of $2 \mathrm{~g} / \mathrm{l}$ with $91 \%$. The lowest mortality rate was $69 \%$ observed at $1.5 \mathrm{~g} / \mathrm{l}$ concentration with ethanolic extract. The larvicidal bioassay values for $A$. squamosa bark methanol extract, C. indicum leaf ethyl acetate extract, and T. procumbens leaf acetone extract $(\mathrm{LC} 50=93.80,39.98$, and $51.57 \mathrm{mg} / \mathrm{l}$; LC90 $=524.90,145.70$, and $226.56 \mathrm{mg} / \mathrm{l}$ ) against the larvae of $A$. Subpictus, whereas for A. squamosa bark methanol extract, C. indicum leaf methanol extract, and T. procumbens leaf ethyl acetate against the larvae of C. tritaeniorhynchus were calculated to be $\mathrm{LC} 50=104.94$, 42.29 , and $69.16 \mathrm{mg} / \mathrm{l} ; \mathrm{LC} 90=443.79,172.34$, and $287.21 \mathrm{mg} / \mathrm{l}$, respectively. The obtained bioassay data were analyzed using Chi-squared test with an established significance level at $P<0.05$ (Kamaraj et al., 2011). The leaf extract of $M$. hortensis has the highest sensitivity to II instar larvae of $C$. quinquefasciatus with their lowest LC values (LC50 83.18 and LC90 190.5 ppm), whereas lower

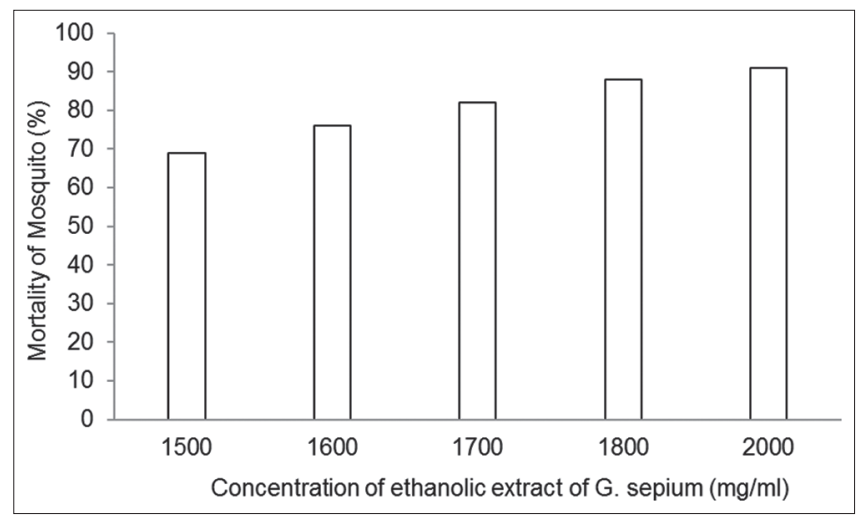

Figure 1: Larvicidal bioassay using ethanolic extract of Gliricidia sepium on Aedes aegypti susceptibility was shown by IV instar larvae of $A$. stephensi (LC50 223.9 and LC90 426.6 ppm) (Kaushik and Saini, 2011).

\section{Analysis of Variance (ANOVA)}

Triplet values from the mortality data were subjected to one-way ANOVA from which the Standard error and critical difference were calculated. From the analysis result, it was observed that the highest significant difference obtained was between 1.5 and $2 \mathrm{~g} / \mathrm{l}$ concentration of all extracts. However, no significant difference was observed between other concentrations of extracts (Table 3). It was concluded that among the three solvent extracts taken, ethanolic extract was the one with highest larvicidal activity. From the above experiment, a significant difference was observed between 1.5 and $2 \mathrm{~g} / \mathrm{l}$ concentration of G. sepium ethanolic extract. Thus, it was concluded that $2 \mathrm{~g} / \mathrm{l}$ concentration of the ethanolic extract showed high larvicidal activity against the larvae of $A$. aegypti (Table 4). The petroleum ether extract of Eucalyptus has no significance different at $0.125 \%$ and $0.500 \%$ concentration, whereas $P>0.05$ level for 0.250 and $1 \%$ concentration (Karthikeyan et al., 2012).

\section{TLC}

150 fractions were collected and subsequently checked for analytes. Only 50 fractions were found to show some spots or smear on the plates, and 10 fractions were found to show visible spot in TLC. The compounds were identified based on the retention factor $\left(\mathrm{R}_{\mathrm{f}}\right)$ values as well as the colors they exhibited.

From the Table 5, $\mathrm{R}_{\mathrm{f}}$ values $0.59 \mathrm{~cm}, 0.27 \mathrm{~cm}, 0.61 \mathrm{~cm}$, $0.25 \mathrm{~cm}, 0.88 \mathrm{~cm}, 0.64 \mathrm{~cm}, 0.78 \mathrm{~cm}, 0.46 \mathrm{~cm}, 0.53 \mathrm{~cm}$,

Table 3: ANOVA single factor-larvicidal bioassay of G. sepium with different solvent extracts

\begin{tabular}{lcccc}
\hline & \multicolumn{4}{c}{ Mean of mortality } \\
\hline Concentration $(\mathrm{mg} / \mathrm{l})$ & 500 & 1000 & 1500 & 2000 \\
Ethanol & 2.66 & 4.66 & 7 & 9 \\
Acetone & 0.33 & 2 & 4.33 & 3.33 \\
Iso-propanol & 1.33 & 3.33 & 6.33 & 4.66 \\
$\mathrm{SE} \pm$ & 0.47 & 0.9 & 0.9 & 1.3 \\
$\mathrm{CD}$ at $P=0.05$ & 2.42 & 4.64 & 2.04 & 4.02 \\
\hline
\end{tabular}

SE: Standard error, CD: Critical difference, G. sepium: Gliricidia sepium

Table 4: ANOVA single factor-larvicidal bioassay of $G$. sepium with ethanolic extract

\begin{tabular}{lccccccc}
\hline $\begin{array}{l}\text { Concentration } \\
\text { (mg/l) }\end{array}$ & 1500 & 1600 & 1700 & 1800 & 2000 & $\mathrm{SE} \pm$ & $\mathrm{CD}$ at \\
Mean of mortality & 5 & 7.33 & 7 & 8 & 8.66 & - & - \\
\hline
\end{tabular}

SE: Standard error, CD: Critical difference, G. sepium: Gliricidia sepium, ANOVA: Analysis of variance 
Table 5: Analysis of different TLC plates

\begin{tabular}{lccc}
\hline Fractions & $\begin{array}{c}\text { Distance traveled } \\
\text { by analyte }(\mathrm{cm})\end{array}$ & $\begin{array}{c}\text { Distance traveled } \\
\text { by solvent }(\mathrm{cm})\end{array}$ & $\begin{array}{c}\text { Rf value } \\
(\mathrm{cm})\end{array}$ \\
\hline F 1 & 3.7 & 6.2 & 0.59 \\
F 2 & 1.7 & 6.5 & 0.27 \\
F 3 & 3.5 & 5.9 & 0.61 \\
F 4 & 1.6 & 6.7 & 0.25 \\
F 5 & 6 & 6.8 & 0.88 \\
F 6 & 4.1 & 6.4 & 0.64 \\
F 7 & 4.4 & 5.7 & 0.78 \\
F 8 & 2.4 & 5.9 & 0.46 \\
F 9 & 3.2 & 6.0 & 0.53 \\
F 10 & 4.2 & 6.2 & 0.67 \\
\hline
\end{tabular}

TLC: Thin layer chromatography

and $0.67 \mathrm{~cm}$ with brown, light brown, blackish green, yellowish brown, blue, violet, and green, respectively, confirmed the presence of saponins, terpenoids, tannins, triterpenoids, alkaloids, and flavonoids. The larvicidal activity of the plant extract may be attributed to the presence of active compounds like terpenoids, saponins, and steroids. The potency of G. sepium was due to the presence of saponins, phenolic compounds, essential oils, and flavonoids (Akharay et al., 2012).

\section{CONCLUSION}

In the present study, the ethanolic extract of G. sepium leaves was found to have an inhibitory effect on the growth of larvae of $A$. aegypti. It was concluded that the ethanolic extract of G. sepium was the most effective when compared to other solvent extracts by the mortality rate of A. aegypti. In the statistical analysis, the highest significant difference was observed between 1500 and $2000 \mathrm{mg} / \mathrm{l}$ concentration of ethanolic extract and other extracts. However, no significant difference was observed in other concentrations. The larvicidal activity of the plant extract may be attributed to the presence of active compounds such as terpenoids, saponins, and steroids which were confirmed by TLC studies and phytochemical analysis.

Phytochemical analysis of aqueous and ethanolic extract confirmed the presence of flavonoids, steroids, saponins, phlobatannins, glycoside, and carbohydrates. Thus, the larvicidal activity of leaf extract of G. sepium may be due to the presence of compounds such as saponins, flavonoids, terpenoids, triterpenoids, and alkaloids. The direct and indirect contribution of such compounds in the efficiency of killing larvae and fitness need to be properly understood to guide the use of botanical insecticide for the management of $A$. aegypti. Natural insecticides may play an important role in future regarding the control of mosquitoes and may thus contribute for the control of vector transmitted diseases such as malaria, dengue fever, and many others. Thus, this work is contributing evidence for the potentiality of botanicals in the public health integrated management.

\section{ACKNOWLEDGMENT}

The authors hearty acknowledge to The Management, Principal and Head of the Department, Department of Biotechnology, K. S. Rangasamy College of Technology, Tiruchengode, for provided support to carry out this work. The authors are thankful to Mr. Pradeep Kumar, for the help rendered toward English correction and aligning of the manuscript.

\section{REFERENCES}

Abdelouaheb A, Nassima R, Noureddine S. Larvicidal activity of a neem tree extract against mosquito larvae in Republic of Algeria. Jordan J Biol Sci 2009;2:15-22.

Ajaieoba EO. Phytochemical and anti-bacterial properties of Parkia biglobosa and Parkia bicolour extracts. Afr J Biomed Res 2002;5:125-9.

Akharay FC, Boboyae B, Adetuyi FC. Anti-bacterial, phytochemical and anti-oxidant activities of the leaf extracts of Gliricidia sepium and Spathodea campanulata. World Appl Sci J 2012;16:523-30.

Arthi N, Murugan K. Effect of Vetiveria zizanioides L. Root extracts on the malarial vector Anopheles stephensi liston. Asian Pac JTrop Dis 2012;2:154-8.

Arunachalam N, Tewari SC, Thenmozhi V, Rajendran R, Paramasivan R, Manavalan R, et al. Natural vertical transmission of dengue viruses by Aedes aegyptiin Chennai, Tamil Nadu, India. Indian J Med Res 2008;12:395-7.

Balasubramanian M. Study on phytochemical screening and antibacterial activity of Nyctanthes-arbortristis. J Chem Pharm Res 2012;4:1686-95.

Choochote W, Tueton B, Kanjanapothi D, Rattanachanpichoi E, Chaithong U, Chaiwong P, et al. Potential of crude seed extract of celery, Apium graveolens L. against the mosquito Aedes aegypti (L.) (Diptera: Culicidae). J Vec Ecol 2004;29:340-6.

Fang F, Sang S, Chen KY, Gosslau A, Ho CT, Rosen RT. Isolation and identification of cytotoxic compounds from Bay leaf (Laurus nobilis). Food Chem 2005;93:497-501.

Fulmali PV, Walimbe A, Mahadev PV. Spread, establishment \& prevalence of dengue vector Aedes aegypti in Konkan region, Maharashtra. Indian J Med Res 2008;127:589-601.

Gowthami M, Tamilselvi S. Phytochemical analysis and antibacterial properties of leaf extract of Azima tetracantha (Lam.). Asian J Plant Sci Res 2012;2:110-4.

Honorio NA, Cabello PH, Codeco CT, Lourenco R. Preliminary data on the performance of Aedes aegypti and Aedes albopictus 
immatures developing in water-filled tires in Rio de Janeiro. Mem Inst Oswaldo Cruz 2006;101:225-8.

Joji Reddy L, Beena J. Evaluation of antibacterial activity of the bark, flower and leaf extract of Gliricidia sepium from South India. Int J Curr Pharm Res 2010;2:18-20.

Kamaraj C, Bagavan A, Elango G, Zahir AA, Rajakumar G, Marimuthu S, et al. Larvicidal activity of medicinal plant extracts against Anopheles subpictus \& Culex tritaeniorhynchus. Indian J Med Res 2011;134:101-6.

Karthikeyan V, Sivakumar K, Aishwarya G, Mohanasundaram S. Studies on larvicidal activity of Leucas aspera, Vitex negundo and eucalyptus against Culex quinquefasciatus collected from Cooum river of Chennai, India. Asian J Pharm Clin Res 2012;5:189-92.

Kaushik R, Saini P. Larvicidal activity of leaf extract of Millingtonia hortensis (Family: Bigniniaceae) against Anopheles stephensi, Culex quinquefasciatus and Aedes aegypti. J Vec Borne Dis 2008;45:66-9.
Meena TI, Jolly CI. A study of the phytochemical composition and antibacterial activity of Holostemma adakodien schultes. Int J Pharm Tech Res 2011;3:1208-10.

Mehta K, Patel BN, Jain BK. Phytochemical analysis of leaf extract of Phyllanthus fraternus. Res J Rec Sci 2013;2:12-5.

Singh RK, Dhiman RC, Mittal PK. Mosquito larvicidal properties of Momordica charantia Linn. (Family: Cucurbitaceae). JVec Borne Dis 2006;43:88-91.

Srivastava A, Bartarya R, Tonk S, Srivastava SS, Maharaj Kumari K. Larvicidal activity of an indigenous plant, Centratherum anthelminticum. J Environ Biol 2008;29:669-72.

Srivastava VK, Singh SK, Rai M, Singh A. Toxicity of Nerium indicum and Euphorbia royleana lattices against Culex quinquefasciatus mosquito larvae. Nig J Nat Prod Med 2003;7:61-4.

Zoran B, Slavica B, Sandra S. Flavanoids from the flower of Linum capitatum kit. Facta Univ 2004;3:67-71. 